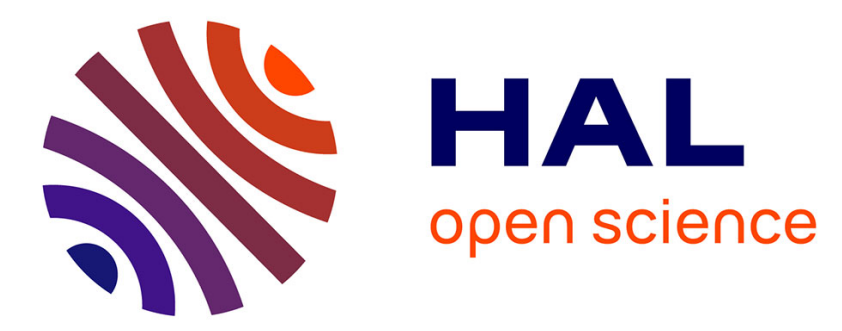

\title{
Understanding subsidence consequences on masonry structures using large small-scale physical modeling
}

Luyen Nghiem, Marwan Al Heib, Fabrice Emeriault

\section{To cite this version:}

Luyen Nghiem, Marwan Al Heib, Fabrice Emeriault. Understanding subsidence consequences on masonry structures using large small-scale physical modeling. 8th International Conference on Physical Modelling in Geotechnics (ICPMG 2014), Jan 2014, Perth, Australia. pp.1195-1202. ineris-00971263

HAL Id: ineris-00971263

https://hal-ineris.archives-ouvertes.fr/ineris-00971263

Submitted on 27 Aug 2018

HAL is a multi-disciplinary open access archive for the deposit and dissemination of scientific research documents, whether they are published or not. The documents may come from teaching and research institutions in France or abroad, or from public or private research centers.
L'archive ouverte pluridisciplinaire HAL, est destinée au dépôt et à la diffusion de documents scientifiques de niveau recherche, publiés ou non, émanant des établissements d'enseignement et de recherche français ou étrangers, des laboratoires publics ou privés. 


\title{
Understanding subsidence consequences on masonry structures using large small-scale physical modeling
}

\author{
L. Nghiem and M. Al Heib \\ INERIS - 60550-Verneuil-en-Hallate - France \\ F. Emeriault \\ ENSE3 - Grenoble INP, Laboratoire 3SR, Grenoble- France
}

\begin{abstract}
Underground movement is an important hazard. The impact of the subsidence on existing structures and infrastructures can be dramatic. A large small-scale physical model, soil-structure interaction model, is developed to study the behavior and the damage of a masonry structure. Displacements and strains of the soil and the structure are measured by using Digital Image Correlation (DIC). Two high quality cameras have been used to follow the development of cracks. A specific algorithm based on the identification of the relative displacement of cracks was developed. The paper summarizes the main results of the masonry damage under the vertical displacements. The location of cracks on the masonry structure depends on the location of the structure on the subsidence trough; the maximum damages are observed when the structure loses the support and the contact with soil.
\end{abstract}

\section{INTRODUCTION}

Shrinkage and swelling of clays, ground water lowering, mining activities and collapse of natural cavities can induce the subsidence of ground surface. The occurrence of subsidence on the ground surface can be very damaging to structures and infrastructures and to the safety of the populations. Damages depend on two main components the subsidence (intensity and extension) and the structure (position, characteristics, materials, shape, age and design). Recently, several research works have been focusing on the analysis of the soil-structure interaction phenomena due to ground movements induced by tunnels and cavities excavation (Potts \& Addenbrooke, 1997, Caudron et al. 2007, Laefer et al. 2012, Giardina, 2012). Different approaches were investigated: in situ monitoring of real structures, small-scale physical model under normal gravity (1g) or in centrifuge and numerical modelling (Bransby et al., 2008, Castro et al., 2007).

In the last decade, we carried-out several research projects to take into account, the interaction between soil and structure using numerical and $1 \mathrm{~g}$ physical models (Hor et al., 2011). In particular, a large small-scale physical model has been designed to reproduce the phenomena and assess qualitatively and to certain quantitatively the soil-structure interactions and the vulnerability of masonry structures (typically individual houses). The design of this physical model is presented in this paper, in particular the system used to reproduce ground surface dis- placement profiles and the displacement measurement system based on Digital Image Correlation (DIC) and its validation in Greenfield conditions (without the structure). A methodology was developed for the assessment of soil-structure interaction in the case of a masonry structure under the impact of underground movements. It is illustrated in 2 cases: the structure is first represented by an equivalent slab model, the second model representing the masonry as an assembly of blocks with no consideration of mortar in the joints (only frictional resistance is accounted between blocks). This paper presents the results of the masonry structure using wood pieces. A particular attention is paid to the determination of the vulnerability assessment basing on the cracks characteristics.

\section{SUBSIDENCE DESCRIPTION AND CONSEQUENCES}

\subsection{The mechanism of subsidence}

Subsidence due to mine operation and the collapse of natural and man-made cavities corresponds to the collapse of the ground surface over areas where mineral ores have been removed. Subsidence causes ground surface deformation resulting in a range of problems from deep holes with vertical sides that pose physical threats to people, to more 
subtle forms of subsidence characterized by sagging and hogging of the ground surface producing more damage, over larger areas, affecting nearly all structures. Figure 1 presents the theoretical curves of vertical displacement, horizontal displacement, tilt, horizontal strain and curvature in the case of mining, similar curves can be proposed in the case of tunneling. The subsidence characteristics depend on the characteristics of underground cavities (depth, area, etc.). The influence angle $\gamma$ determine the boundaries of the zone of potential impact of subsidence on structures and infrastructures. The maximum damages are generally observed in structures that are located in maximum tilt and in the zone of maximum horizontal extension strain defined by the angle $\theta$ (Figure 1).

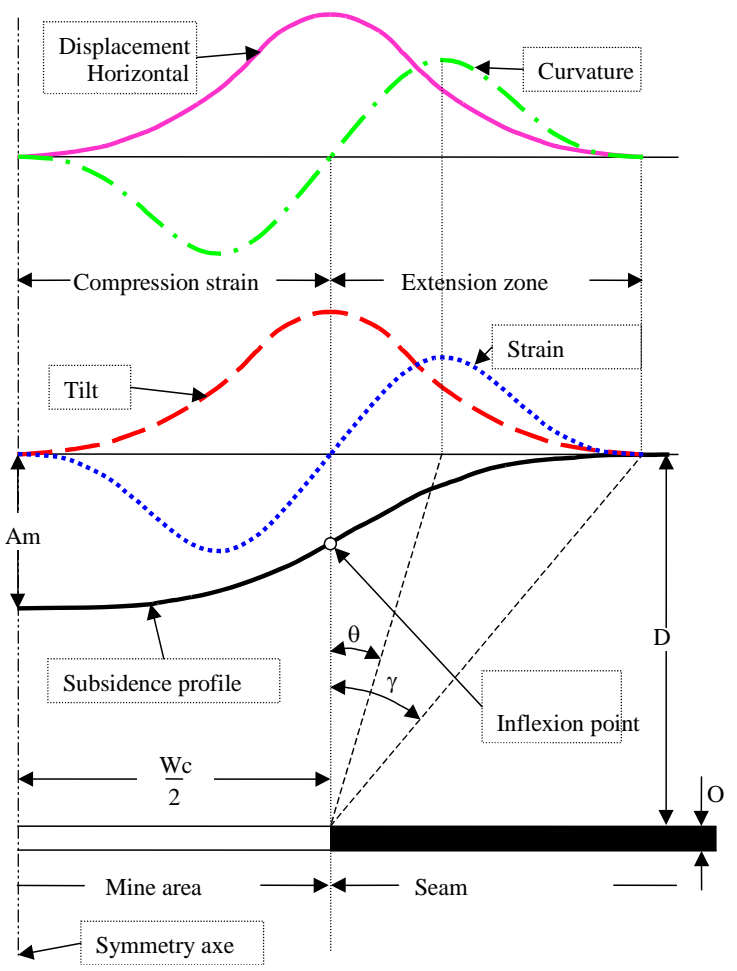

Figure 1. Subsidence Parameters (O: layer open, Am: maximal subsidence, $\gamma$ and $\theta$ : influence angle and maximum strain angle, D: depth, Wc: critical width) maximum strain angle, D: depth, Wc: critical width)

\subsection{Damage of structures}

The impact of subsidence on buildings and infrastructures has become an important and costly environmental issue during mining and after the closure of mines. The vertical component of ground movements causes changes in ground gradient, which can adversely affect (Boone, 2002, Mair, 2011). The tilt, horizontal strains (extension and compression) and curvature are the causes of the most commonly observed types of damage (Deck, 2002). Extension is characterized by pulled open joints in masonry. The compressive strains result in the squeezing-in of voids: such as doors and windows and the horizontal movements of masonry blocks. The intensity of the horizontal strain is generally used as the key parameter to assess the level of damage (from light to very severe, Deck, 2002). The strain of the soil may induce cracks on the structure. The class of damage depends on the opening of the crack.

\subsection{Design of the INERIS small-scale physical model}

The physical model design depends on the goals of the tests and the constructive characteristics of the prototype. The physical model must be a true scalar representation of the prototype (Garnier, 2002). The length scale that defines the model dimension is considered as fundamental quantity within design of the model. The boundary conditions must enable the model to move and deform in a manner similar to the prototype. According to the postulates, the physical model is designed to be used in $1 \mathrm{~g}$ environment (earth gravity, Hor et al., 2011).

The objective of the physical model is to simulate the effect of the surface ground movements due to mining and underground cavities on structures. The large small-scale model has to be able to hold a soil block of $3 \times 2 \times 1 \mathrm{~m}$ with a maximum geometric scale of 1/50 (ratio between the physical model and the prototype). The main hypothesis of the INERIS physical model is that it does not represent the collapse of the cavity itself, but only focuses on the phenomena at surface level (Figure 2). The movements at ground surface are achieved by vertical downwards movements of "electric jacks" placed at the bottom of the model. The cross-section of the actuator is limited to $250 \times 250 \mathrm{~mm}$, corresponding to up to $12.5 \times 12.5 \mathrm{~m}$ at prototype scale. The apparatus is indeed limited to localized phenomena: sinkhole or collapse/subsidence of small-extent.

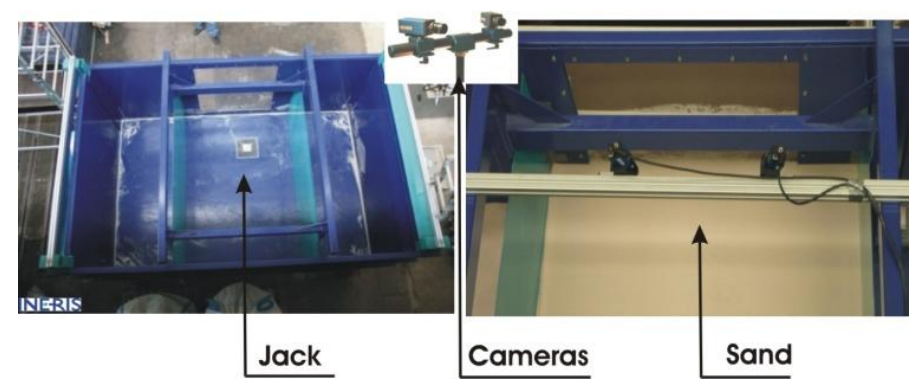

Figure 2. Large small scale physical model for modeling surface subsidence and damage structures

\subsection{Measurement technique}

Measurement of surface displacements is achieved by means of stereo digital imagery (ManChao et al., 2009). Digital Image Correlation (DIC) technique was adopted to determine the displacements and the deformations. This allows monitoring the whole top surface of the ground and more especially where ground movements happen. The relative position of the 2 cameras is very precisely 
known and allows the determination of 3D displacements and deformations of the soil and structure surfaces (Figure 2).

The two high-resolution digital cameras have a maximum frequency of 8 images/second at full resolution. They have to be calibrated before the start of a test by the use of a test pattern. A good calibration allows obtaining very precise measurements with an error of 1/100 of a pixel in good conditions: this corresponds to $10 \mu \mathrm{m}$ when 1 pixel is equal to $1 \mathrm{~mm}$. In the tests presented later in this paper, this ratio is close to 2 pixels per millimeter. But, because the sand used in the experiments cannot be considered as a true continuous media (being constituted of small particles), the corresponding maximal error has been evaluated and happens to be close to 0.10 pixel (corresponding to $0.05 \mathrm{~mm}$ ), which is still a good performance (White et al., 2003).

The main disadvantage of this method of monitoring is the huge volume of data created by a single test. With a volume of 8 Mo per capture (two images of 4 Mo each) and considering the maximum frequency of capture, it represents near 2 Go of raw data to be stored each minute. For a full test and with the exploitation files for the digital correlation process, this corresponds to a total required memory between 30 and 40 Go. The localization of the cracks (opening joints) is determined using the image quality indicator. When a crack created the continuity of displacements is generally lost and corresponds to the localization of a crack.

\section{ASSESSMENT OF SOIL-STRUCTURE INTERACTION WITH SIMPLIFIED STRUCTURE MODELS}

\subsection{The structure}

In order to study the effects of the soil-structure interactions during the occurrence of a subsidence trough, an individual house is adopted for testing. The reference geometry for the building is based on the analysis of an existing database of individual buildings damaged by mining subsidence in the east of France (Deck, 2002). A typical $10 \mathrm{~m}$ x $10 \mathrm{~m}$ twofloor house constituted of masonry walls (Young modulus: $6000 \mathrm{MPa}, v=0.3$ ), reinforced concrete slabs (Young modulus: $30000 \mathrm{MPa}, v=0.2$ ) and shallow foundations are considered. This realistic prototype scale model has been simplified in order to define the small-scale model. The studies conducted so far concern only particular masonry houses. The simulation of a house was first performed by a slab of polycarbonate (Hor et al., 2011). The work was carried out in 2011 were devoted to physical modeling of a masonry structure more realistic. The research has led to separate the structure into two parts: the first corresponds to the foundations and the second concerns the bearing elements, including walls. The components of the masonry pieces were formed by wood pieces (Figure 3). The Wood (Azobé - very dense wood) has been proposed. They were cut so as to respect the similarities between the masonry blocks and pieces of wood (1/40). Table 1 summarizes the characteristics of the pieces of wood. The foundation corresponds to silicon material.

Table 1. Characteristics of the wood pieces used for the construction of the masonry structure

\begin{tabular}{|l|c|}
\hline Characteristics & $\begin{array}{c}\text { Azobé } \\
\text { wood }\end{array}$ \\
\hline Density $\left(\mathrm{kN} / \mathrm{m}^{3}\right)$ & 10.32 \\
\hline Longitudinal Young modulus $(\mathrm{GPa})$ & 17 \\
\hline Friction angle $\left(^{\circ}\right)$ & 30 \\
\hline Compression strength $(\mathrm{MPa})$ & 96 \\
\hline Dimensions of woods pieces $(\mathrm{mm})$ & $14 * 7 * 7 *$ \\
\hline
\end{tabular}

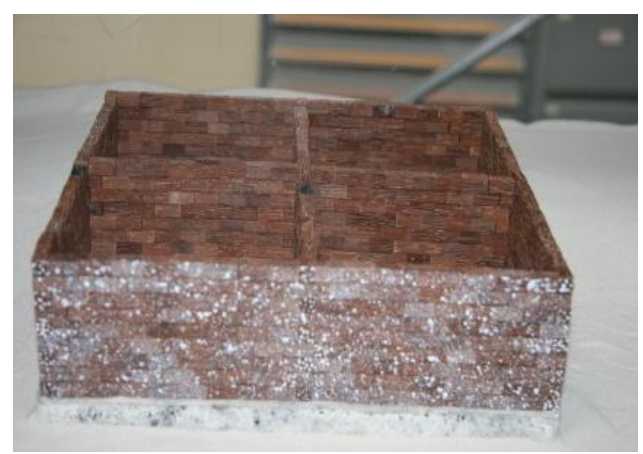

Figure 3. Physical model of masonry structure using wood pieces

\subsection{Identification of the damage}

The macroscopic deformation of the wall is calculated by the following relations (Eq. 1, Figure 4):

$$
\left\{\begin{array}{l}
\varepsilon_{A B}=\frac{L_{A B}-L}{L} \\
\varepsilon_{C D}=\frac{L_{C D}-L}{L}
\end{array}\right.
$$

With $\mathrm{L}_{\mathrm{AB}}$ and $\mathrm{L}_{\mathrm{CD}}$ are: the final top length and down length of the wall. 


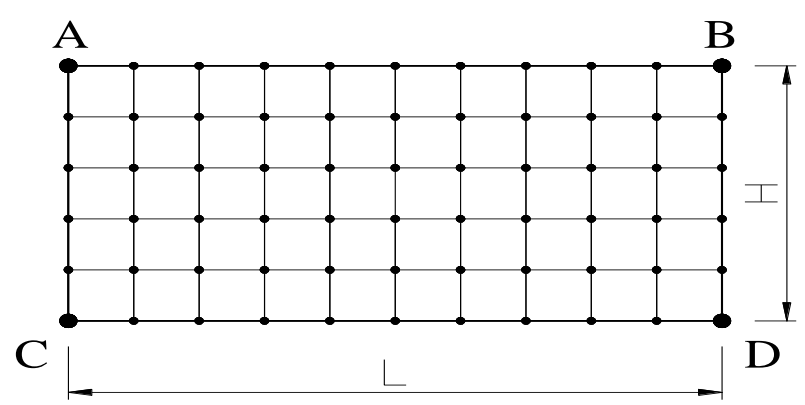

Figure 4. Global mesh of the wall for determining the global deformation

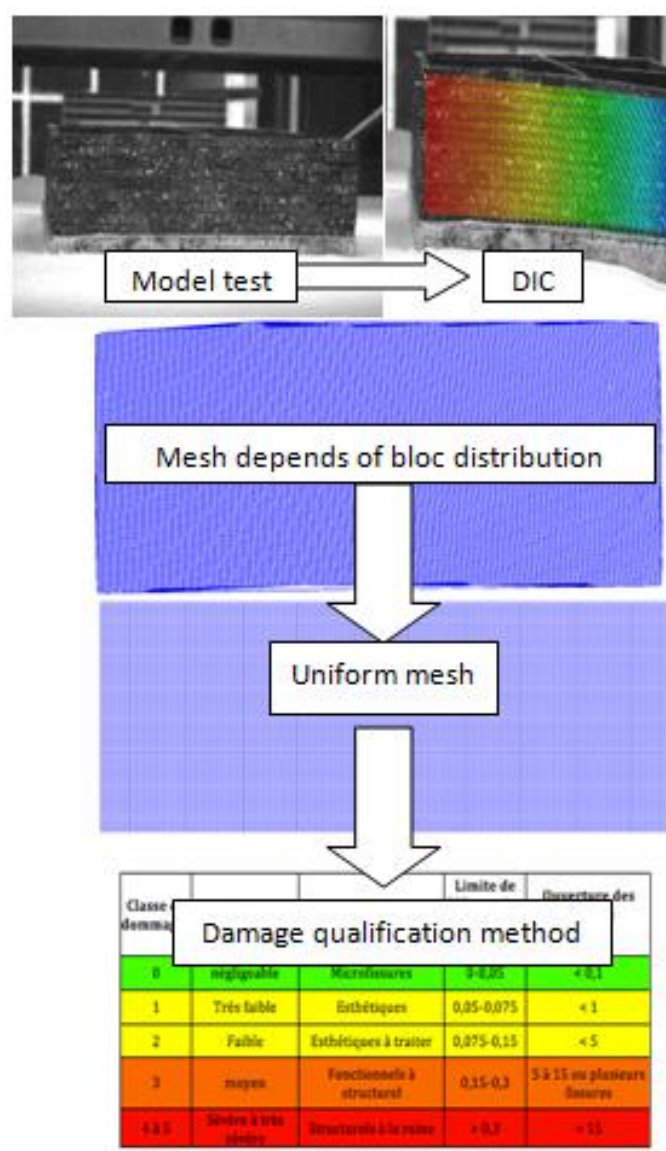

Figure 5. Steps of the calculations and the localization of damage of masonry structure

To determine the damage of masonry blocks, a methodology was developed basing on the following steps:

Step 1: Subsidence is reproduced using an electric vertical jack with the physical model. These movements are captured by four cameras fast high resolution.

Step 2: Analysis of captured photos using the VIC-3D software. One chooses the size of the window correlation and no correlation; we analyze the acquired images on the front wall (only one wall is filmed).

Step 3: The values of the displacements of the points of the wall surface may be represented in a non-uniform mesh. The collected information, for each point of the grid point, are the coordinates ( $\mathrm{x}, \mathrm{y}$, $\mathrm{z})$, the vertical displacement (v), the horizontal displacement $(\mathrm{u})$ and the movement out of the plane (w).

Step 4: The initial data, which is in a non-uniform mesh due to the distribution of blocks, be required to interpolate a uniform mesh (Figure 4). Then we determine the coordinates of the joints between blocks.

Step 5: The quantification of the relative displacements of the blocks, including the openings gives the quantification of damages. Damage rankings are derived from Figure 5 indicating that the rankings 4 and 5 are combined into a single classification called "severe and very severe." The principle for calculating the openings of the blocks is shown in Figure 6.

One considers two points close to the interface as shown in detail 1 (Figure 6). The movements of

$$
\left\{\begin{array}{l}
\vec{u}_{p}=\vec{u}_{i}+\vec{v}_{i} \\
\vec{u}_{p}=\vec{u}_{i+1}+\vec{v}_{i+1}
\end{array}\right.
$$

these two points are decomposed into a normal displacement $\left(\mathrm{u}_{\mathrm{i}}\right)$ and tangential displacement $\left(\mathrm{v}_{\mathrm{i}}\right)$ such that:

For the classification of damage that does not include slippage of the blocks, only the normal component (u) of displacement is taken into the calculation. Thus, the difference in displacement normal i write the interface:

The cracks appear only at the joints due to the rigid blocks. So, the classification point $\Gamma i$ is performed by comparing the value with the threshold value. Finally, the relative cumulative length for each category of damage is determined by the following equation (3):

$$
l_{D_{i}}^{*}=\frac{\left(m_{D_{i}}-1\right) \Delta p}{\sum l_{j}}
$$

Where:

$-1^{*}$ Di Is the length on cumulative damage to the classification of Di;

- $m_{D i}$ is the number of points of the interface associated with $\mathrm{D}_{\mathrm{i}}$ ranking;

- $\Delta \mathrm{p}$ : step length of the uniform mesh;

$-\Sigma \mathrm{l}_{\mathrm{j}}$ : is the sum of length of the seams.

It is noted that is proportional to the number of joints classified Di. Indeed, it is difficult to determine the precise length method proposed classification of damage. This is caused by the distribution of points in a fairly random for each classification of damage. 


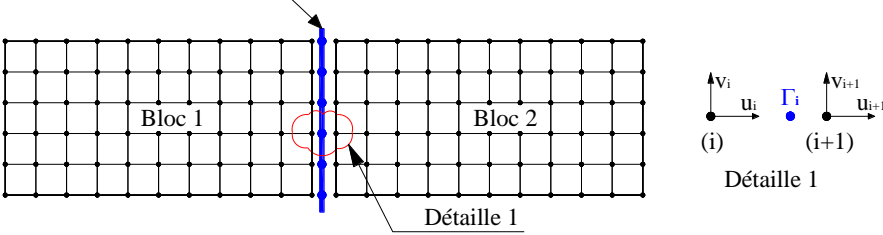

Figure 6. Crack identification by the relative displacement of the grid points of two blocks

\subsection{Results and discussion}

The un-reinforced masonry structure was tested for three positions relative to the position of subsidence trough (Figure 7). From the tests performed in this study: structure in P1 is located in a compression, structure in $\mathrm{P} 2$ is located on the area of the maximum tilt and the P3 is structure subjected to a complex loading (tension to compression in the longitudinal direction and to the transverse direction).
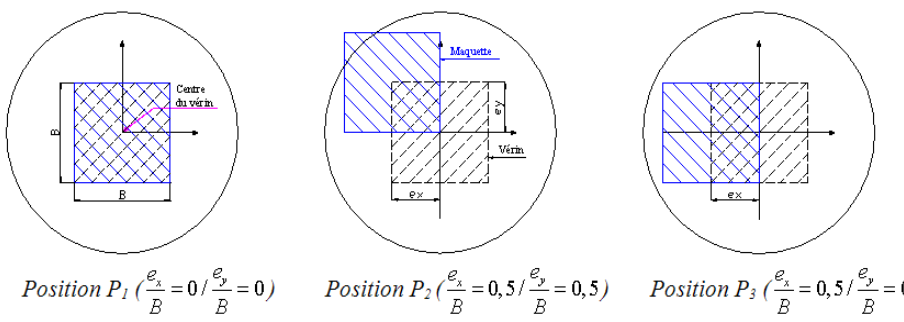

$B$ : width of the structure, e: distance between the center of the structure and the center of the jack

Figure 7. Position of masonry structure and the jack

Figure 8 presents the induced subsidence due to the vertical displacement of the jack (position 2). The maximum vertical displacement varies from 13 $\mathrm{mm}(\mathrm{P} 1)$ to $28 \mathrm{~mm}$ (P3). The horizontal strain of the wall varies from $0.2 \%(\mathrm{P} 1)$ to $1 \%(\mathrm{P} 3)$. Figure 9 shows the location of the open joints, we note that the first class corresponding to openings less than $0.1 \mathrm{~mm}$ is distributed randomly.

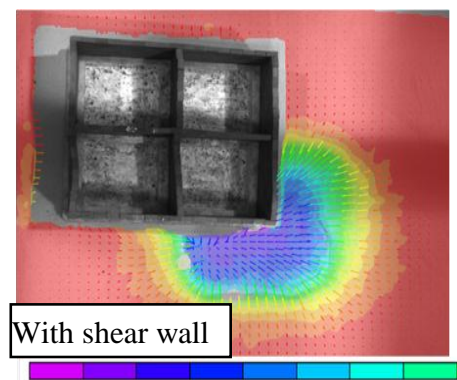

$-28 \mathrm{~mm}$

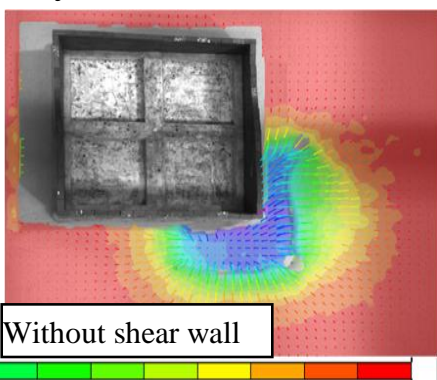

$0 \mathrm{~mm}$

Figure 8. Subsidence through of the soil and the masonry structure (with and without shear wall), position P2
The class 3 and 4 (yellow and red) are located according to the position of the structure. Class 5 (severs damage) corresponds to the opening of joints greater than $15 \mathrm{~mm}$ dependent on the position of the structure relative to the subsidence. This class is almost demeaning to the position $\mathrm{P} 1$; however continue fractures are formed for positions $\mathrm{P} 2$ and $\mathrm{P} 3$. This result highlights the importance of location and total length as a parameter to assess the damage to the masonry structure.

Table 2 compares the damage classes for the three positions (P1, P2 and P3, Figure 7) of the structure without shear walls. Several results are interesting for a vertical displacement of $30 \mathrm{~mm}$, corresponding to $1.2 \mathrm{~m}$ in the case of a prototype.
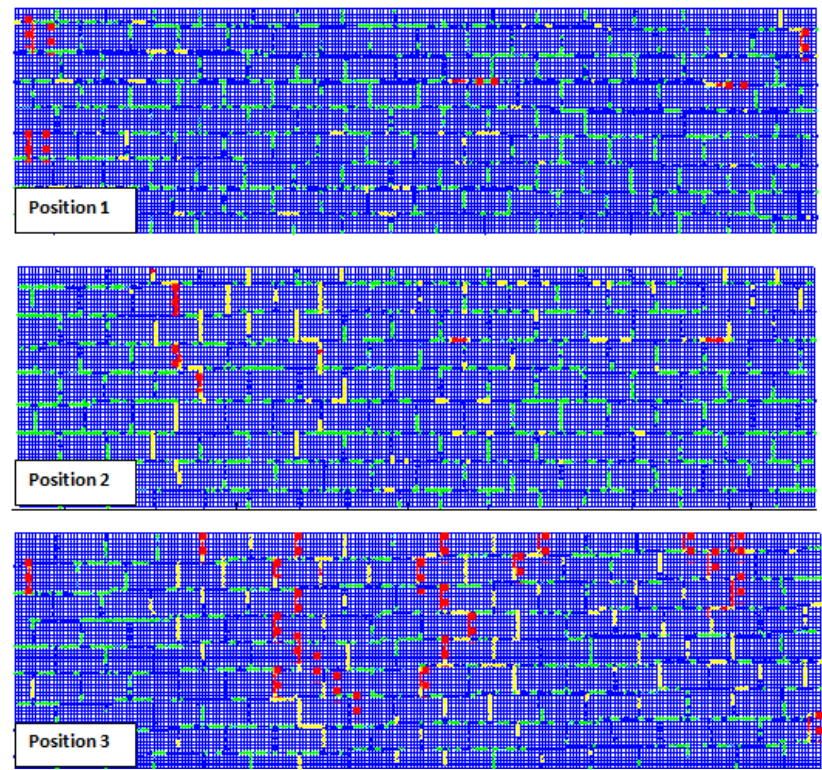

Figure 9. Localization of induced cracks (red and discotinu line) in the masonry structure for different structure positions

- Classes 1 and 2 are not discriminatory for damage to the structure and location of cracks, there is little difference between the three positions;

- Class 3 (medium damage) and above Class 4 (severe to very severe damage) depends strongly on the position of the structure relative to the cylinder. The position P1 of structure remains generally satisfactory in steady state. In contrast, the structure in position 3 is badly damaged with the loss of structural integrity. Note that all three positions are affected by class 4 damage. In contrast, the degree of damage depends on the position of the structure; we cannot consider them the same level of vulnerability as conventional methods advocated. These results are not yet applicable for different conditions because of the materials (sand and lack of cohesion). Efforts will continue to bring more land under real conditions and masonry structures. 


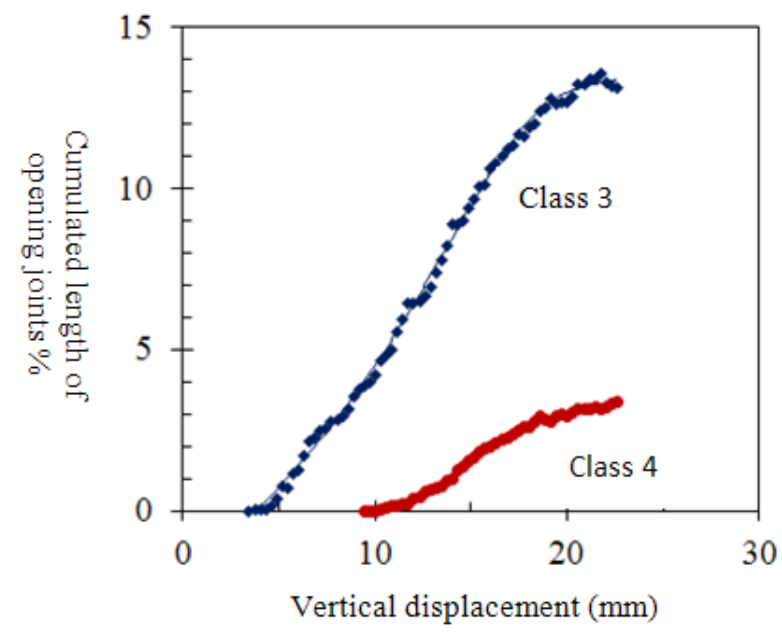

Figure 10. Evolution of the cumulated length of opening joints (class 3 and 4) for different vertical displacements of the jack

Table 2. Damage classes due to vertical dispalcement (30 $\mathrm{mm})$ for different positions

\begin{tabular}{|c|c|c|c|}
\hline \multirow{2}{*}{ Damage class } & \multicolumn{3}{|c|}{ Masonry structure position } \\
\cline { 2 - 4 } & P1 & P2 & P3 \\
\hline Class 1 & 38 & 40 & 30 \\
\hline Class 2 & 45 & 40 & 40 \\
\hline Class 3 & 4 & 6 & 14 \\
\hline Class 4 & 0,5 & 1 & 5 \\
\hline
\end{tabular}

\section{CONCLUSION}

The large small-scale physical model of the soil and structure was developed to study the vulnerability of masonry structure due to subsidence. The masonry structure was modeled using dense wood pieces. An algorithm was developed to determine the potential of damaging and crack characterization. Three positions of the surface structure in a subsidence through were studied: structure in the tension zone, in the compression zone and finally in the mixed zone (tensioncompression). In terms of vulnerability (damage), the structure compression zone has the least damage; the structure in the mixed zone of tensioncompression has the most damage (sever class), while the structure in tension zone is the intermediate position. For the most dangerous factors, buckling off-plan dominant position in compression, tension and bending are the main factors of damage in the pull position.

\section{REFERENCES}

Allersma, 1995. Simulation of subsidence in soil layers in a geotechnical centrifuge. Land Subsidence (Proceedings of the Fifth International Symposium on Land Subsidence, The Hague, October 1995). IAHS Publ. no. 234, 1995. 117

Bachmann D. 2006. Modélisation physique tridimensionnelle des mouvements gravitaires de grande ampleur en milieu rocheux. Thèse $(\mathrm{PhD})$ Université de Nice-Sophia Antipolis. PP 140.

Boone, S. J. 2002. Assessing construction and settlementinduced building damage: a return to fundamental principles.Rep., 559-570 pp, Golder Associates Inc., California.

Burd H.J., Houlby G., Augarde C., Liu G. 2000. "Modelling tunneling-induced settlement of masonry building". Proc. Inst. Civ. Eng. Geotech. Engng, 143:17-29

Bransby M., Davies M. and Nahas A. 2008. "Centrifuge modelling of normal fault-foundation interaction". Bull. Earthquake Eng. 6:585-605.

Castro R, Trueman R, Halim A. 2007. “A study of isolated draw zones in block caving mines by means of a large $3 \mathrm{D}$ physical model". Int J Rock Mech Min Sci 2007;44:86070.

Caudron M., Emeriault F. \& Al Heib M. 2007. Contribution of the experimental and numerical modeling to the understanding of the soil-structure interaction during the event of a sinkhole. ECSMGE 2007, Madrid.

Deck, O. 2002. "Etude des conséquences des affaissements miniers sur le bâti: proposition pour une méthodologie d'évaluation de la vulnérabilité du bâti," thèse, Institut National Polytechnique de Lorraine, France.

Garnier, J. 2002. "Properties of soil samples used in centrifuge models" Proc. Physical Modelling in Geotechnics: ICPMG, St Johns, Canada, 5-19.

Giardina G., Marini A., Hendriks M.a, Rots J. a, Rizzardini F: 2012. Experimental analysis of a masonry façade subject to tunneling-induced settlement. Engineering Structures 45 (2012) 421-434

Hor B., Caudron M., Al Heib M. 2011. Experimental analysis of the impact of ground movements on surface structure. Pan-America conference on soil mechanics and geotechnical engineering. Toronto, CANADA

Laefer, D. F., Erkal, C., Cording E.J., Long J.H, Troung Hong L., 2010, Theoretical solutions for strength-scaled unreinforced masonry for soil-structure experimentations. Journal. Of testing and Evaluation, 38 (4):449-457.

Man-chao HE, GONG Wei-li, LI De-jian, ZHAI Hui-ming 2009. Physical modeling of failure process of the excavation in horizontal strata based on IR thermography. Mining Science and Technology 19 (2009) 0689-0698.

Mair R. 2011. Tunneling in urban areas and effects on infrastructures, Advances in research and practice, Muir Wood, Lecture 2011, N$^{\circ}$ ISBN : 978-2-9700624-4-8, AITES

Potts D. and Addenbrook T. 1997. "A structure's influence on tunnelling induced ground movements". Proc. Inst. Civ. Eng. Geotech. Eng. 125 (2), 109-125.

White D., Take W. and Bolton M. 2003. Soil de formation measurement using particle image velocimetry (PIV) and photogrammetry". Geotechnique, 53:619-631 